\title{
Determinants of Bachelor Students' Intention to Enter a Research-Oriented Career
}

\author{
Dirk Heerwegh (corresponding author) \\ Janssen, Pharmaceutical Companies of Johnson\&Johnson \\ Turnhoutseweg 30, 2340 Beerse, Belgium \\ Email: dirk.heerwegh@telenet.be \\ Jef C. Verhoeven \\ Centre for Sociological Research, University of Leuven \\ Parkstraat 45 - box 3601, 3000 Leuven, Belgium \\ Email: Jef.verhoeven@soc.kuleuven.be \\ Kurt De Wit \\ Data Management Unit, University of Leuven \\ Krakenstraat 3 - box 5200, 3000 Leuven, Belgium \\ Email: kurt.dewit@kuleuven.be
}

Received: March 24, 2015 Accepted: June 4, 2016 Published: June 23, 2016

doi:10.5296/jet.v3i2.9206 URL: http://dx.doi.org/10.5296/jet.v3i2.9206

\begin{abstract}
The career opportunities of university bachelor students are multiple. Some bachelor students might consider a career in research. In this article, we explore, first, the degree to which bachelor students in a research intensive university intend to enter a research-oriented career, and second, the factors influencing this intention. 1,232 students of a research-intensive university answered an on line questionnaire. $4.08 \%$ scored 4 or higher out of 5 on a scale that measures the intention to become a researcher. A regression model $\left(\mathrm{R}^{2}=.47\right)$ showed that among a set of 13 variables, the attitude towards research proved to have the strongest influence on the intention to enter a research-oriented career, next to gender, and study major. The occupational focus, frequency of use of ICT (information and communication technologies) instruments, and the opinion that scientific research needs ICT have a negative influence.
\end{abstract}

Keywords: Research career, student, study orientation, ICT use, scientific research 


\section{Introduction}

The career opportunities of university bachelor students are multiple and depend among other things on the discipline they are studying and on their own aspirations. Some bachelor students, regardless of the discipline, might consider a career in research, inside or outside academia. A research-intensive university especially might offer a good breeding ground for future researchers. Labini and Zinovyeva (2011, p. 340), looking at the research activity of universities, observed that "the quality of academic research is positively correlated with the likelihood of undertaking a research-oriented career". A research-intensive university is not one-dimensional, according to Mohrman, Ma and Baker (2008). They discern eight characteristics in their "emerging global model of the research University": "global mission, research intensity, new roles for professors, diversify at funding, worldwide recruitment, increasing complexity, new relationships with government and industry, and global collaboration with similar institutions". Many universities make progress on one or several of these characteristics, and this is also true for the university where our research took place. Therefore it is interesting to check whether a substantial part of the young students at this university see for themselves a research career in later professional life.

The purpose of this study is twofold. The first objective is to describe the extent to which second and third year bachelor students (in three-year bachelor programs) of a research-intensive university intend to enter a research-oriented career. The second objective is to determine which factors influence the intention of these students to enter a research-oriented career.

To answer these questions we rely on data we collected in a survey focused on the study of the relationship between openness for research and mastery of basic information and communication technologies (ICT) skills among bachelor students (De Wit, Heerwegh \& Verhoeven, 2014). In the context of that survey, data were collected about the expectations of the students concerning their future professional career and relevant variables for understanding the choice for that particular career. This secondary analysis (Pole \& Lampard, 2002) has the advantage that the data are collected by the same researchers.

We consider three groups of variables that might have an effect on students' career intentions and from which we will inductively build an explanatory model: the motivation and the attitudes of the students; their socialization in terms of gender, age, education level of the parents, and domain of study; and their attitudes towards and frequency of use of ICT. This latter series of variables has been included because of the tremendous impact of ICT on the development of scientific research (Uhlir \& Schröder, 2007; Silvestrini, 2013). But although ICT might be very functional for scientific research, it is not so that all students have the same proficiency level in ICT and the same positive attitude towards working with a computer (De Wit et al., 2014). Therefore we conjectured that these variables regarding ICT might have consequences for choosing for a research career.

In this article, we will first describe these three groups of variables in more detail and introduce our hypotheses. Then we will explain which questionnaire items were used to measure these variables and how we used the questionnaire in a research conducted at a large 
research-intensive university. Next, we will present the results of that research. And finally, we will discuss the results and draw conclusions from them.

\section{Variables and Hypotheses}

The intention of bachelor students to enter a research-oriented career will be influenced by many factors. In this article, we focus on three groups of variables: four variables regarding the motivation and the attitudes of the students, four variables concerning the socialization of students, and four ICT-related variables. For each we give a short explanation and formulate a hypothesis for our research.

The first variable regarding motivation and attitude that may contribute to the explanation of the students' intention is the 'academic self-concept' of the student (Bennett, 2009). Bandura (1993) suggests that the belief of an actor in his/her capacities to engage successfully in a particular behavior (self-efficacy) is an important motivation for an actor. Lent, Brown and Hackett (1994) sympathize with this idea and develop a cognitive career theory in which self-efficacy plays a role, next to expected outcome, goal orientation, contextual and personal characteristics, and learning factors. In a follow-up study of Canadian BA graduates Zafira (2012) observed that high ability students pursued more a graduate degree than others. In the current study, we interpret self-efficacy more specifically as the belief of the actor that s/he has the capacity of being a successful student in the chosen scientific field, and thus as a potentially important factor to influence the intention to enter a research-oriented career. More in particular we use the notion of 'academic self-concept' (Bennett, 2009), to measure the extent to which someone believes he or she is successful as an academic student (Gainor, 2006; Dasan, 2013). The hypothesis is that students with a higher score on academic self-concept, will be more inclined to enter a research-oriented career.

A second variable is the attitude of the students towards research. Several researchers have observed a positive relationship between attitude towards science and choosing an academic education in science among students (Venville, Rennie, Hanbury \& Longnecker, 2013). Guerin, Jayatilaka and Ranasinghe (2015) call this intrinsic motivation and saw it as a strong motivator among Australian students to pursue a higher degree by research. We hypothesize that students who are more positive towards research, will be more inclined to enter a research-oriented career.

A third element is the vocational orientation of students. For most students, higher education is the last stage in preparation for professional life. Although study choice is not the same as occupational choice, there certainly is an important link between both. We conjecture that students who think of themselves as future researchers are also the ones who are more motivated to invest in studying (Vermunt, 1994). Consequently, it is expected that there will be a positive relationship between higher levels of vocational orientation and the intention to enter a research-oriented career.

A fourth variable that might have influence on the option of students to become a researcher can be found in a certain preference for what Gottfredson (1981) called "acceptable occupational alternatives" (Dasan, 2013). Therefore we asked students how strongly they 
preferred a job where they should mainly provide information, organize work of others, offer advice, etc. Our hypothesis was that the more students choose for the alternatives of conducting research the less they would choose for a research job.

Besides motivation and attitudes, the intention to enter a research-oriented career may also be affected by the context in which socialization takes place. Depending on society's culture, persons are socialized into roles that differ in the extent to which doing research is accepted as part of these roles. Four variables are considered in this study: gender, the age of the students, the domain of study, and the education level of the parents.

Many researchers have observed that women are still outnumbered by men in the faculty (Blickenstaff, 2005). As a consequence, students meet fewer female than male faculty, which might diminish the motivation of female students to enter a research-oriented career (Dasan, 2013). Duffy and Sedlacek (2007) also stressed that female students are more interested in working with people than in other types of work. More specifically, Kamphuis (2007) observed that girls lose their belief in their academic capacities and in that they have a future in science over the course of their academic education (see also Cheryan \& Plaut, 2010). And Zafira (2012) observed that women are less likely pursuing graduate degrees than men. George (2006) calls science still a 'male-dominated profession'. More in general, gender role socialization traditionally does not support a positive attitude towards science among women (Messersmith, Garrett, Davis-Kean, Malanchuk \& Eccles, 2008; Hartman \& Hartman, 2008; Eccles, 2009). Our hypothesis therefore is to find differences in intention to become a researcher between female and male students.

Research has shown that the age of the actors might or might not have some influence on career choice. In a study of career choice among first year graduate students Wertheim, Widom and Wortzel (1978) observed that older female students choose more for a traditionally female career, whereas the age of the male students did not show any difference in career choice. In a survey among high school students and college juniors in the USA, Neice and Bradley (1979) found that age is extremely important for the decidedness of students for a particular career: the older the students grow the least indecisive they are concerning their career. Nevertheless, age has not always a significant influence on relevant factors determining a career choice. In a study of 150 future ICT teachers in India, Bhattacharya (2015), concluded that there was no difference between the different age groups of the students as far as motivation for and interest in becoming a teacher, and the inclination toward research is concerned.

Moreover, many researchers (Osborne, Simons \& Collins, 2003; Barmby, Kind \& Jones, 2008; Bennett \& Hogarth, 2009; Potvin \& Hasni, 2014) have come to the conclusion that the interest and attitude to school science decreases in secondary schools when students are older than eleven years. This statement is not always confirmed. Barmby et al. (2008) mention some studies making the opposite observation: the attitude of students towards science does not decrease in the beginning of secondary education. Furthermore, Bennett and Hogarth (2009) and Potvin and Hasni (2014) observe that at the end of secondary school the interest of students for out-of-school science grows and that students see themselves choosing for a 
science career. Although these observations are not immediately connected with a research career, they show that the attitude towards research might change depending on the age of the student, and this might also have its consequences for career choice.

In Western society, research in sciences has a more outspoken position than research in humanities. Significantly more money is invested in the sciences than in the humanities, which is also visible in the development of research in both domains (Eurostat, 2009). Each of these domains has its own culture and stresses differently the position of research and the interaction between students and faculty in research (Lin \& Ha, 2009; Eagan Jr, Sharkness, Hurtado, Mosqueda, \& Chang, 2011). Following from these observations, we hypothesize that science students are more directed to and more open for scientific research than humanities students, when we compare students by their domain of study.

Woolnough (1994, as quoted in Kamphuis, 2007), Zafira (2012), and Guerin et al. (2015) state that the attitudes of students towards science and technology as a vocation and as a domain of study also depend on the home culture. Students who grow up in families where science and research receive some recognition, show a more positive attitude towards science (although this is less so for female students) or are more interested in attending graduate school. Therefore we will check whether students whose fathers or mothers have enjoyed a university training will be more open for research than other students. This indicator might be not specific enough, because we do not have information about the attitude of the parents toward research. Nevertheless, its seems to us reasonable to suppose that university educated parents are more open for scientific research than parents who did not enjoy this training.

A last series of variables that may help to explain the intention to enter a research-oriented career among students is their socialization in the current ICT culture. There is a relationship between the research-oriented identity commitment of students and the use they make of ICT, although the relationship is diversified and not very strong (Verhoeven, Heerwegh \& De Wit, 2016). To further explore this relationship we formulate two hypotheses. First, we want to find out whether students who more strongly recognize that modern research depends to some extent on ICT will be more inclined to enter a research-oriented career. Second, we hypothesize that students who for their study use a personal computer, a number of ICT programs, or a number of ICT-instruments more frequently, might be more inclined to enter a research-oriented career.

\section{Method}

\subsection{Procedure and Participants}

This study was conducted at the University of Leuven (KU Leuven), one of the largest Belgian universities. In its mission statement, this university calls itself a 'research-intensive, internationally oriented university that carries out both fundamental and applied research' (KU Leuven, 2012). On its web site, it is stated that: 'Study programmes are research-based and organized within an innovative interdisciplinary framework' (KU Leuven, 2016), and: 'The university's vision of teaching and learning emphasizes the close link between research and education' (AcademicPositions.eu, 2016). In the description of the university's bachelor 
programmes on the website, these objectives are mentioned throughout as leading the bachelor education. Moreover, most of these descriptions also stress the necessity for students to learn modern technologies of information communication. It hence seems that research and modern ICT have been adapted as part of the basic university culture.

The research population consisted of all second and third year bachelor students of the mentioned university $(\mathrm{N}=3,609)$. In Belgium a bachelor programme takes three years, i.e., 180 ECTS (European Credit Transfer System). This population was chosen to balance two objectives. On the one hand we intended to study the attitudes and intentions of students that had completed at least one academic year, so that they would have a fairly sound understanding of what scientific research actually entails. On the other hand we were interested in the development of attitudes towards becoming a researcher as early in the curriculum as possible.

An online questionnaire was used to collect the data. The questionnaire was available for a duration of four weeks, during which 1,232 students $(34 \%$ of 3,609$)$ completed it after an initial e-mail invitation and two reminders if necessary. A small proportion of the sample was aged over 25 years. These students were excluded from the sample. Because the sample distribution for gender, age, and faculty deviated to some extent from the population distribution, a weighting factor was calculated by iterative proportional fitting. The weighted sample contains $54.1 \%$ females, and $45.9 \%$ males. The mean age was 20.0 years $(\mathrm{SD}=1.30)$. Most students reported a major in Arts (17.4\%), followed by Medicine (14.4\%), Economics and Business (12.4\%), Law (11.5\%), Engineering Science (10.5\%), Psychology and Educational Sciences (7.7\%), Social Sciences (5.2\%), Sciences (5.0\%), Bioscience Engineering (4.4\%), Pharmaceutical Sciences (4.0\%), Kinesiology and Rehabilitation Sciences (3.4\%), Theology and Religious Studies (2.2\%), and Philosophy (2.1\%).

The research hypotheses are tested with linear regression analysis of the model shown in Figure 1. Data were checked for normality, multicollinearity, and heteroscedasticity. Some evidence of heteroscedasticity led us to use robust regression analysis instead of ordinary regression analysis. Scales were constructed with the help of principal factor analysis and in case more than one factor could be distinguished we used a promax rotation. All analyses were performed using SAS ${ }^{8} 9.2$.

\subsection{Measures}

In this section we explain how the variables described above were measured in our online questionnaire.

The dependent variable in our research model is the intention to enter a research-oriented career. This variable was measured by asking the participants to indicate the degree to which they agreed with statements regarding their future jobs (see Table 1). It was our intention to offer students a wide range of possible vocational options that can be pursued after graduation, and not push them into the direction of research. Responses were collected on a 5-point Likert scale, ranging from 'totally not true for me' (score 1) to 'this is totally true for me' (score 5) with the midpoint 'this is more or less true for me'. Factor analysis showed that 
the items referring to a research career belonged to the same dimension. Cronbach's $\alpha$ was .90. Factor analysis was used to calculate factor scores (DiStefano, Zhu, \& Mîndrilặ, 2009). These factor scores are used to estimate the regression model (see Figure 1). The items referring to other career outlooks similarly turned out to form a dimension (see Table 1, factor 2). Cronbach's $\alpha$ was .68.

Turning then to the independent variables in our research model, the first set of variables regards the students' motivations and attitudes.

Academic self-concept was measured by 6 items such as: 'I rate myself highly in terms of my academic ability as an undergraduate' and 'I have great self-confidence in my ability to succeed academically at university' (Cronbach's $\alpha=.83$ ). This instrument was translated from Bennett (2009). The response options to these items where the same as for the dependent variable; factor scores were calculated and used in the estimation of the regression model.

The attitude towards scientific research was measured with an instrument inspired by Cheung (2009) who used it to assess the attitude towards chemistry. The instrument was adapted and included 12 items such as: 'Scientific research is fun'; 'Everyone should be familiar with scientific research because it touches everyone's life'; and 'I want to spend more time reading books about scientific research' (Cronbach's $\alpha=.87$ ) (see Table 2). The response options to these items varied between 'I totally disagree' (score 1) and 'I totally agree' (score 5) and factor scores were calculated and used in the estimation of the regression model.

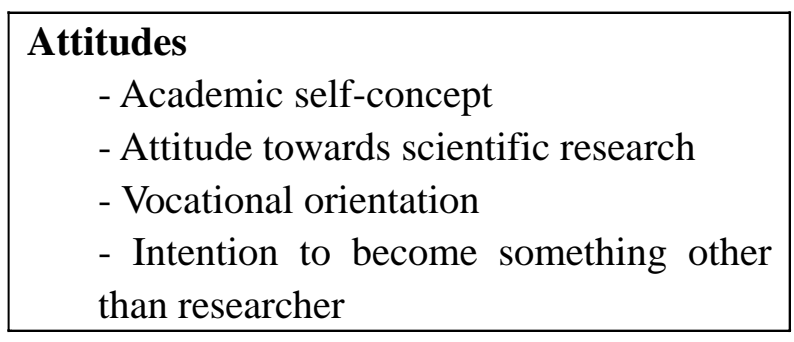

\section{Context}

- Gender

- Age

- Domain of study (science vs. others)

- University education father

- University education mother

\section{ICT culture}

- Scientific research needs ICT

- Use of PC for study

- Use of ICT instruments for study

- Use of ICT programs for study

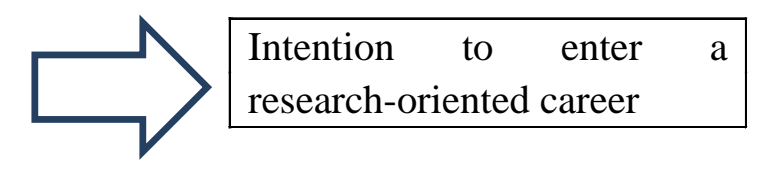

Figure 1. Explanatory model 
Table 1. Rotated factor pattern for the intentions to enter a research-oriented or another career (Standardized Regression Coefficients)

\begin{tabular}{|l|r|r|}
\hline Items & Factor & Factor \\
& 1 & 2 \\
\hline 1. I would like to do research in my future job. & $\mathbf{9 0}$ & -.08 \\
\hline 2. I would like to become a researcher in a company. & $\mathbf{. 7 6}$ & -.07 \\
\hline 3. I would like to teach about scientific research in my future job. & $\mathbf{. 6 1}$ & .19 \\
\hline 4. I would like to become a researcher at a university or college. & $\mathbf{. 8 1}$ & -.06 \\
\hline $\begin{array}{l}\text { 5. I would like to get a job in which I will have some part in scientific } \\
\text { research. }\end{array}$ & $\mathbf{. 8 2}$ & -.02 \\
\hline $\begin{array}{l}\text { 6. During my training I would like to concentrate on doing scientific } \\
\text { research. }\end{array}$ & $\mathbf{. 8 5}$ & -.04 \\
\hline $\begin{array}{l}\text { 7. Schools should especially prepare us for conducting scientific } \\
\text { research. }\end{array}$ & $\mathbf{. 5 7}$ & .14 \\
\hline 8. In my future job I would like to organize the work of collaborators. & .22 & $\mathbf{. 5 2}$ \\
\hline 9. In my future job I would like to inform people. & .09 & $\mathbf{. 5 6}$ \\
\hline 10. In my future job I would like to give advice to clients or patients. & -.14 & $\mathbf{. 5 6}$ \\
\hline 11. In my future job I would like to make plans for others. & .09 & $\mathbf{. 6 0}$ \\
\hline 13. In my future job I would like to mainly work with people. & -.22 & $\mathbf{. 5 3}$ \\
\hline
\end{tabular}

Note. The highest loadings are marked in bold.

Table 2. Factor pattern for the attitude of students toward scientific research

\begin{tabular}{|l|r|}
\hline Items & Factor 1 \\
\hline 1. Scientific research is fun. & .78 \\
\hline 2. Scientific research bores me. & -.69 \\
\hline 3. Scientific research is the most interesting that we learn here. & .65 \\
\hline 4. I would enjoy university more if they did not bother us with scientific research. & -.59 \\
\hline $\begin{array}{l}\text { 5. One would have to give more space to conduct scientific research in our } \\
\text { training. }\end{array}$ & .60 \\
\hline \begin{tabular}{l} 
6. Lessons about scientific research are a waste of time. \\
\hline 7. Scientific research allows to solve everyday problems.
\end{tabular} & -.47 \\
\hline $\begin{array}{l}\text { 8. Everyone should be familiar with scientific research because it touches } \\
\text { everyone's life. }\end{array}$ & .39 \\
\hline $\begin{array}{l}\text { 9. How to conduct scientific research should be one of the main subjects at the } \\
\text { university. }\end{array}$ & .41 \\
\hline 10. I want to spend more time reading books on scientific research. & .69 \\
\hline 11. I would like to solve problems of scientific research. & .75 \\
\hline 12. If I get the chance, I will definitely do scientific research. & \\
\hline
\end{tabular}


The 'vocational orientation' of a student was measured with a Likert scale developed by Vermunt (1994). The instrument contained five items among which: 'What I want to acquire above all through my studies is a vocational skill' and 'The main goal I pursue in my studies is to prepare myself for a vocation' (Cronbach's $\alpha=.73$ ). The response options to these items were the same as for the dependent variable; factor scores were calculated and used in the estimation of the regression model. This scale is labelled 'vocational orientation' in the remainder of this text.

Five items were used to measure the intention of the students to become something other than a researcher (see Table 1, factor 2). These items were offered with the same response options as the dependent variable. These items similarly turned out to form a dimension (see Table 1, factor 2). Cronbach's $\alpha$ was .68.

The second set of independent variables, as explained in previous sections, refers to the socialization context.

Gender is represented in the model as a dummy variable $(1=$ female, $0=$ male $)$. Students in one of the science faculties (Sciences, Engineering Sciences, Bioscience Engineering) were scored 1 while the other students were scored 0 . The economic and cultural background of the student's family was summarized with the study level of the parents: whether the father is a university graduate $(1=$ yes, $0=$ no $)$ and whether the mother is a university graduate $(1=$ yes, $0=$ no).

Age is also included in the model, but as a control variable; no specific hypotheses are formulated with regard to this variable.

The last set of independent variables describes the degree to which students are immersed in ICT culture. Four variables were constructed. A first variable refers to the opinion of students that a certain level of command of ICT skills is necessary for conducting scientific research. Nine items were offered, such as: 'A scientific researcher must be able to properly work with database software'; 'A scientific researcher must be able to solve basic computer problems'; and 'A scientific researcher must be able to keep in touch with his colleagues using the internet' (Cronbach's $\alpha=.86$ ) (See Table 3). The response options to these items where the same as for the attitude towards scientific research; factor scores were calculated and used in the estimation of the regression model.

Three variables referred to the frequency of use of ICT, more in particular the frequency of use of a computer, of other hardware, and of software. The frequency of computer use was measured by asking participants how frequently they had surfed the Internet, used e-mail, used chat, searched the Internet in a goal-oriented way, downloaded music or film, participated in newsgroups, and had written blogs or wikis during the weeks preceding the survey. These questions used the response scale, daily (score $=6$ ); four to five times a week $($ score $=5)$; two or three times a week $($ score $=4)$; weekly (score $=3)$; monthly $($ score $=2)$; less than once a month (score $=1)$, or never (score $=0$ ). The average score of each student, calculated on all items of a variable, was used for further analysis.

The use of ICT hardware was covered by items concerning the use of PC or laptop, Internet, 
mobile, iPad or tablet, iPod or MP3, iPhone or smartphone, digital camera, and e-reader. The items about the frequency of use of software referred to: word processing, spreadsheet, database, social network sites (such as Twitter), virtual learning environments, drawing software, statistical programs, qualitative data analysis programs, and specialized software. These questions used the same response scale as used for the frequency of computer use. Here too the average score of each student, calculated on all items of a variable, was used for further analysis.

Table 3. Factor pattern for the link between scientific research and ICT

\begin{tabular}{|l|r|}
\hline Items & Factor 1 \\
\hline 1. Today, a scientific researcher cannot work properly without a computer. & .49 \\
\hline 2. A scientific researcher must be able to properly work with a word processor. & .76 \\
\hline 3. A scientific researcher must be able to properly work with a digital spreadsheet. & .69 \\
\hline 4. A scientific researcher must be able to properly work with a presentation program. & .74 \\
\hline 5. A scientific researcher must be able to properly work with a database software. & .70 \\
\hline 6. A scientific researcher must be able to properly work with a drawing program. & .44 \\
\hline $\begin{array}{l}\text { 7. A scientific researcher must be able to properly investigate databases of his domain of } \\
\text { study on the Internet. }\end{array}$ & .67 \\
\hline $\begin{array}{l}\text { 8. A scientific researcher must be able to keep in touch with his colleagues using the } \\
\text { internet. }\end{array}$ & .64 \\
\hline 9. A scientific researcher must be able to solve basic computer problems. & .59 \\
\hline
\end{tabular}

\section{Results}

The first objective of this study was to describe the extent to which bachelor students intend to enter a research-oriented career. Table 4 shows the mean scores and standard deviations of each of the items in the intention to enter a research-oriented career scale. All averages on each individual item are below the midpoint of the response scale (3), which indicates a relatively low intention to enter a research-oriented career.

When using the calculated factor scores, and rescaling these to assume values within the range of the original items $(1-5)$, the average scale score is 2.45 ( $\mathrm{SD}=0.93)$. Moreover, despite the high appreciation of research in the mission statement of the university at which the study was conducted, only $4.08 \%$ of the students scored 4 or higher out of 5. Table 4 shows that these students appreciate the most participation in research, and the least teaching about scientific research, but the average scores on each item do not exceed the midpoint of the response scale (3/5). Students score higher for openness for other occupations than those involving research: the average score is 3.27 out of 5. Occupations focused on managing or advising are more attractive to a major group of students at this stage in their higher education career. 
Table 4. Average scores and standard deviations for the items of the "intention to enter a research-oriented career" scale

\begin{tabular}{|l|l|l|l|}
\hline Item & $\mathrm{N}$ & $\mathrm{M}$ & $\mathrm{SD}$ \\
\hline 1. I would like to do research in my future job. & 1,165 & 2.61 & 1.16 \\
\hline 2. I would like to become a researcher in a company. & 1,166 & 2.38 & 1.13 \\
\hline 3. I would like to teach about scientific research in my future job. & 1,169 & 1.94 & 1.02 \\
\hline 4. I would like to become a researcher at a university or college. & 1,169 & 2.38 & 1.16 \\
\hline $\begin{array}{l}\text { 5. I would like to get a job in which I will have some part in scientific } \\
\text { research. }\end{array}$ & 1,167 & 2.94 & 1.13 \\
\hline $\begin{array}{l}\text { 6. During my training I would like to concentrate on doing scientific } \\
\text { research. }\end{array}$ & 1,164 & 2.39 & 1.03 \\
\hline \begin{tabular}{l} 
7. Schools should especially prepare us for conducting scientific research. \\
\hline
\end{tabular} & 1,169 & 2.60 & 0.99 \\
\hline
\end{tabular}

It is instructive to look at the correlation matrix of the dependent and independent variables. Five of the twelve independent variables have a significant correlation with a research oriented career. There is - not surprisingly - a strong and significant relationship between the intention to enter a research oriented career and a positive attitude towards scientific research $(\mathrm{r}=.71, \mathrm{p}<.0001)$. The four other correlations with the intention are weaker, but still significant: academic self-concept $(\mathrm{r}=.19, \mathrm{p}<.0001)$, gender (male students score higher) $(\mathrm{r}$ $=-.21, \mathrm{p}<.0001)$, science students $(\mathrm{r}=.23, \mathrm{p}<.0001)$, and the use of ICT programs for study $(\mathrm{r}=.11, \mathrm{p}=.0002)$ (see Table 5$)$. The observed relationship between a positive attitude towards scientific research and a research oriented career is in line with the finding by Rottinghaus, Lindley, Green and Borgen (2002) that investigative confidence of students (students with strong scientific orientation and interested in research) is related with educational aspirations. Educational aspirations is defined as progression on the different levels of higher education. The higher preference of male students for a research career in comparison with female students finds confirmation by Blickenstaff (2005), Kamphuis (2007), and Cheryan and Plaut (2010). This is not confirmed by Zafira (2012) for students choosing for graduate school: "controlling for ability, aspirations, and confidence" the gender difference is no longer significant.

The correlation matrix also makes clear that there are no significant relationships between the vocational orientation of the students, their choice for another job than researcher, their age, the education level of their parents and most of the variables describing the ICT culture of the students on the one hand and their orientation on a research career on the other hand. There is one exception, although the relationship is weak $(r=.11, \mathrm{p}=.0002)$. Students who work more frequently and with a greater variety of computer programs seem to be more interested in a career as researcher. The statement made by Wertheim et al. (1978) that female students make different career choices than male students, is not confirmed. Both male and female students do not show a different option for a research career according to their age (respectively $\mathrm{r}=-.05, \mathrm{p}=.27 ; \mathrm{r}=-.07, \mathrm{p}=.08$ ). 
The meaning of the academic self-concept for a research oriented career has been stressed above. This factor has nine significant, though weak relations with the twelve other independent variables. A positive self-concept goes together with a positive attitude towards scientific research $(\mathrm{r}=.23, \mathrm{p}<.0001)$, a vocational orientation $(\mathrm{r}=.07, \mathrm{p}=.03)$, a younger age $(\mathrm{r}=-.15, \mathrm{p}<.0001)$, a university degree of father $(\mathrm{r}=.13, \mathrm{p}<.0001)$ or mother $(\mathrm{r}=.12, \mathrm{p}$ $<.0001)$, a belief in the need of ICT for research $(\mathrm{r}=.13, \mathrm{p}<.0001)$, and frequent use of ICT programs $(\mathrm{r}=.09, \mathrm{p}=.004)$. Moreover, there is a trend that male students have a higher academic self-concept than female students $(\mathrm{r}=-.24, \mathrm{p}<.0001)$, and that science students score higher than students of humanities, social sciences or biomedical sciences $(r=.11, \mathrm{p}<.001)$.

As noted above, there is a strong relationship between a positive attitude towards research and the option for a research oriented career $(\mathrm{r}=.71, \mathrm{p}<.0001)$, but the relationships between a positive attitude towards research and the other variables of the model are weak or non-existent.

A strong vocational orientation of the students does not go together with an orientation of the student towards a research career $(r=-.05, p=.08)$. This means that for most students their aspired occupational career is not becoming a researcher. It is however remarkable that vocational orientation and a positive attitude toward scientific research have some weak links with four characteristics of an ICT culture: there is a tendency that students scoring high on these two variables also score high on the conviction that scientific research needs ICT (respectively $\mathrm{r}=.13, \mathrm{p}<.0001 ; \mathrm{r}=.11, \mathrm{p}<.001$ ), on the use of computers for study (respectively $\mathrm{r}=.10, \mathrm{p}=.0011 ; \mathrm{r}=.07, \mathrm{p}=.03)$, and on the use of ICT programs $(\mathrm{r}=.06, \mathrm{p}$ $=.04 ; \mathrm{r}=.16, \mathrm{p}<.0001)$ and ICT instruments $(\mathrm{r}=.13, \mathrm{p}<.0001 ; \mathrm{r}=.08, \mathrm{p}=.008)$ for study. The ICT culture seems to be connected with the future vocational picture of the students. Noteworthy in this context is the moderate correlation between three modes of using ICT by students: students scoring high on computer use for study also score high on using ICT instruments $(\mathrm{r}=.41, \mathrm{p}<.0001)$ and ICT programs $(\mathrm{r}=.43, \mathrm{p}<.0001)$ for study, and students scoring high on the use of ICT programs for study also score high on using ICT instruments for study $(\mathrm{r}=.40, \mathrm{p}<.0001)$.

Contrary to what the theories above suggested, the correlations between the education level of the father and of the mother on the one hand, and the choice for a research oriented career on the other hand do not support the hypothesis that students growing up in families where there is more knowledge about research (university trained parents) will choose for a research career (respectively $\mathrm{r}=.02, \mathrm{p}=.452$ and $\mathrm{r}=.02, \mathrm{p}=.514$ ). This observation seems to confirm the hypothesis that the influence of the socio-economic background of the students on their study progress will diminish during their university study career (Zafira, 2012). But a final answer on this question can only be delivered when the socio-economic background is more specified than only referring at the graduation level of the parents. 


\section{Macrothink}

Journal of Education and Training

ISSN 2330-9709

Table 5. Correlation matrix of the variables of the explanatory model

\begin{tabular}{|c|c|c|c|c|c|c|c|c|c|c|c|c|c|c|}
\hline & $\begin{array}{l}\text { Academic } \\
\text { self-concept }\end{array}$ & $\begin{array}{l}\text { Attitude } \\
\text { towards } \\
\text { research }\end{array}$ & $\begin{array}{l}\text { Vocational } \\
\text { orientation }\end{array}$ & Gender & Age & $\begin{array}{l}\text { Science } \\
\text { student }\end{array}$ & $\begin{array}{l}\text { University } \\
\text { degree } \\
\text { father }\end{array}$ & $\begin{array}{l}\text { University } \\
\text { degree } \\
\text { mother }\end{array}$ & $\begin{array}{l}\text { Scientific } \\
\text { research } \\
\text { needs ICT }\end{array}$ & $\begin{array}{l}\text { PC use } \\
\text { for study }\end{array}$ & $\begin{array}{l}\text { Use of ICT } \\
\text { instruments } \\
\text { for study }\end{array}$ & $\begin{array}{l}\text { Use of ICT } \\
\text { programs } \\
\text { for study }\end{array}$ & $\begin{array}{l}\text { Not } \\
\text { research } \\
\text { career }\end{array}$ & $\begin{array}{l}\text { Research } \\
\text { oriented } \\
\text { career }\end{array}$ \\
\hline $\begin{array}{l}\text { Academic } \\
\text { self-concept }\end{array}$ & 1.00 & & & & & & & & & & & & & \\
\hline $\begin{array}{l}\text { Attitude towards } \\
\text { research }\end{array}$ & $.23 * * *$ & 1.00 & & & & & & & & & & & & \\
\hline $\begin{array}{l}\text { Vocational } \\
\text { orientation } \\
\end{array}$ & $.07 *$ & $.08^{* *}$ & 1.00 & & & & & & & & & & & \\
\hline $\begin{array}{l}\text { Gender (female } \\
\text { vs. male) }\end{array}$ & $-.24 * * *$ & $-.16^{* * *}$ & .06 & 1.00 & & & & & & & & & & \\
\hline Age (years) & $-.15 * * *$ & -.02 & $.07 *$ & -.01 & 1.00 & & & & & & & & & \\
\hline $\begin{array}{l}\text { Science student } \\
\text { (vs. Biomedical } \\
\text { and Humanities) }\end{array}$ & $.11 * * *$ & $.16^{* * *}$ & $-.06^{*}$ & $-.25 * * *$ & $-.21 * * *$ & 1.00 & & & & & & & & \\
\hline $\begin{array}{l}\text { University } \\
\text { degree Father } \\
\text { (yes vs. no) }\end{array}$ & $.13 * * *$ & .06 & $-.06^{*}$ & $-.07 *$ & $-.11 * * *$ & .05 & 1.00 & & & & & & & \\
\hline $\begin{array}{l}\begin{array}{l}\text { University } \\
\text { degree Mother } \\
\text { (yes vs. no) }\end{array} \\
\end{array}$ & $.12 * * *$ & .02 & -.05 & $-.07 *$ & $-.12 * * *$ & $.07 *$ & $.45 * * *$ & 1.00 & & & & & & \\
\hline $\begin{array}{l}\text { Scientific } \\
\text { research needs } \\
\text { ICT }\end{array}$ & $.13 * * *$ & $.11 * * *$ & $.13 * * *$ & .05 & $.09 *$ & -.05 & .02 & -.01 & 1.00 & & & & & \\
\hline $\begin{array}{l}\text { Use of PC for } \\
\text { study }\end{array}$ & 01 & $.07^{*}$ & $.10^{* *}$ & $-.10^{* *}$ & $.11^{* * *}$ & .03 & -.06 & -.03 & $.14^{* * * *}$ & 1.00 & & & & \\
\hline $\begin{array}{l}\text { Use of ICT } \\
\text { instruments for } \\
\text { study }\end{array}$ & .01 & $.08^{* * *}$ & $.13 * * *$ & -.02 & .04 & .03 & -.02 & .01 & $.09^{* * *}$ & $.41 * * *$ & 1.00 & & & \\
\hline $\begin{array}{l}\text { Use of ICT } \\
\text { programs for } \\
\text { study }\end{array}$ & $09^{* *}$ & $.16^{* * *}$ & $.06^{*}$ & $-.10 * * *$ & $-.07^{*}$ & $.24 * * *$ & -.01 & -.01 & $.14 * * *$ & $.43 * * *$ & $.40 * * *$ & 1.00 & & \\
\hline $\begin{array}{l}\text { Not research } \\
\text { career }\end{array}$ & -.05 & .03 & $.23 * * *$ & .04 & $.10 * * *$ & $-.14 * * *$ & -.02 & .02 & $.09^{* * *}$ & $.12 * * *$ & $.12 * * *$ & $.12 * * *$ & 1.00 & \\
\hline $\begin{array}{l}\text { Research } \\
\text { oriented career }\end{array}$ & $.19 * * *$ & $.71 * * *$ & -.05 & $-.21 * * *$ & -.05 & $.23 * * *$ & .02 & .02 & .02 & .03 & -.01 & $.11 * * *$ & .05 & 1.00 \\
\hline
\end{tabular}

Note: $* p<.05, * * p<.01, * * * p<.001$. 
The second objective of this study was to determine which variables influence the intention to enter a research-oriented career. Using all independent variables described previously, the regression model (see Figure 1) explains $47 \%$ of the variance in the dependent variable (See Table 6). We applied the same model on the openness of bachelor students for other vocations and found a much lower $\mathrm{R}^{2}\left(\mathrm{R}^{2}=.10\right) .47 \%$ is a relatively high value, but it is mainly driven by the attitude towards research $\left(\mathrm{B}=.76 ; \chi^{2}=1071.84, \mathrm{p}<.0001\right)$. The positive influence of the attitude towards research on the intention to enter a research-oriented career is in line with our hypothesis. Venville et al. (2013) observed the same, but more specifically for science students. Nevertheless, it is clear that not all variables contribute equally to a better prediction of openness for research.

Table 6. Predictors of intention to enter into a research-oriented career (results from robust linear regression)

\begin{tabular}{|l|l|l|l|l|}
\hline \multirow{2}{*}{ Predictor variable } & \multicolumn{4}{|c|}{ Intention to enter a research-oriented career } \\
\cline { 2 - 5 } & $\mathrm{B}$ & $\mathrm{SE}$ & $\chi^{2}$ & $\mathrm{p}$ \\
\hline Intercept & .52 & .35 & 2.26 & .13 \\
\hline Academic self-concept & .01 & .03 & 0.02 & .90 \\
\hline Attitude towards scientific research & .76 & .02 & 1071.84 & .00 \\
\hline Vocational orientation & -.11 & .02 & 22.88 & .00 \\
\hline Not research career & -.05 & .03 & 3.67 & .06 \\
\hline Gender (female vs. male) & -.11 & .04 & 5.70 & .02 \\
\hline Age (years) & -.02 & .02 & 1.37 & .24 \\
\hline Science student (vs. Biomedical and Humanities) & .23 & .06 & 12.64 & .00 \\
\hline University degree Father (yes vs. no) & -.03 & .05 & 0.36 & .55 \\
\hline University degree Mother (yes vs. no) & .00 & .05 & 0.00 & .96 \\
\hline Scientific research needs ICT & -.06 & .02 & 5.44 & .02 \\
\hline Use of PC for study & -.04 & .03 & 2.1 & .15 \\
\hline Use of ICT instruments for study & -.07 & .04 & 4.08 & .04 \\
\hline Use of ICT programs for study & -.04 & .04 & 0.86 & .35 \\
\hline $\mathrm{R}^{2}$ & .47 & & & \\
\hline Scale & .65 & & & \\
\hline
\end{tabular}

Note: $N=963$

We had also hypothesized that a more positive academic self-concept would positively influence the intention to enter a research-oriented career, but the results show that this factor does not reach statistical significance.

Contrary to our third hypothesis, a more pronounced vocational orientation does not positively influence the intention to enter a research-oriented career, but in fact appears to 
operate in the reverse direction $\left(\mathrm{B}=-.11 ; \chi^{2}=5.7, \mathrm{p}=.02\right)$. This result is in line with the observation above that most students are not preparing themselves to become researchers, and it suggests that those who are most conscious about preparing for a profession, are not thinking of a career in research.

The fourth hypothesis has to be refuted as well. We expected that the less students opted for another than a research job, the more they would choose to become a researcher (Dasan, 2013). Our data did not confirm this hypothesis $\left(B=-.05 ; \chi^{2}=3.67 ; p=.06\right)$.

Turning to the context variables, as expected females are less inclined to choose for a research-oriented career than males. Openness for research is more visible among male than female students (see also Blickenstaff, 2005; Kamphuis, 2007; Cheryan \& Plaut, 2010). Our data also confirm a statement made by Duffy and Sedlacek (2007): women score 4.06 out of 5 on the question 'In my future job I would like to mainly work with people', whereas male students score an average 3.65 out of 5 , which is significantly lower $(\mathrm{p}<.0001)$. Moreover, the more students wish to work with people in their later career, the less open they are for research $(r=-.17 ; \mathrm{p}<.0001)$.

Science students are more inclined to go for a career in research than other students $(\mathrm{B}=.23$; $\left.\chi^{2}=12.64 ; \mathrm{p}<.0001\right)$. This is in line with our hypothesis. On the other hand research by Zafira (2012) in Canada shows that students of Engineering, Math, and Computer Science (which we classified as Science students) pursued less graduate studies than other students.

The hypothesis that students from families in which the mother and/or the father had a university degree would show a greater intention of entering a research-oriented career, is not confirmed. Neither one of the relevant variables reaches statistical significance. (It should be noted that this is not due to collinearity among these variables.)

Regarding the four ICT variables, two show a statistically significant result: students who use ICT instruments for study more intensely are in fact less inclined to enter a research-oriented career $\left(\mathrm{B}=-.07 ; \chi^{2}=4.08 ; \mathrm{p}=.04\right)$, and the more students think that research needs ICT the less motivated they are to become later a researcher in professional life $\left(B=-.06 ; \chi^{2}=5.44 ; p\right.$ $=.02$ ) . Again, this may be seen as congruent with the observation that most students are not preparing themselves for a career in scientific research, but rather for other types of careers.

\section{Conclusion and Discussion}

The second and third year bachelor students of the research-intensive university in our study show some openness for research, but the group that actually considers a research career is limited. Only $4.08 \%$ of these students intends to take this track, a rather small number in a university where research belongs to the core business.

Nonetheless, the data allow to find interesting variables that impact the intention of bachelor students to enter a research-oriented career. In fact, the model has a relatively high coefficient of determination ( $\mathrm{R}^{2}$ close to $50 \%$ ). This is mainly driven by a single variable: the attitude towards research. The results hence confirm, unsurprisingly, that the attitude towards research is an important driver of the intention to enter a research-oriented career. An interesting venue 
for future research would thus be to investigate whether the attitude towards research can be influenced, as this could represent a way to increase the number of students that is interested in pursuing a career in research. For this purpose, it would be needed to look whether the attitude towards research changes throughout the academic career of students. A longitudinal research design could be used to answer this question.

Other variables next to the attitude variable were also found to influence the intention to become a researcher, although these variables showed a less pronounced impact. Students with a major in science have a stronger intention to pursue a research-oriented career, while females, students who are more focused on studying for their future occupation, and students who use ICT instruments more intensely for study purposes, are less inclined to do so. Surprisingly, the age of the students and the education level of the parents did not turn out to be significant variables. The age range of 18-25 years in this research might be too narrow to show differences in a research career choice. In relation to the possible influence of the parents it would be interesting to test in further research more specifically whether students growing up in families whose parents have a research job and/or have a positive appreciation of scientific research prefer more a research oriented career than other students.

Besides former limitations we have to remember that the analysis was carried out on data collected in function of a larger project focused on the study of ICT skills and ICT use by second and third year bachelor students. Moreover, data were collected in one university of a particular university system. A wider sample, national and international, could shed more light on the generality of the presented observations.

Despite the relatively high proportion of explained variance, it is clear that our inductive model can be extended and put into a broader theoretical context. One promising avenue could be the 'expectancy value model of motivated behavioral choice', that goes together with theories of socialization as established by Eccles (2009). Although this model was not used to guide the design of the current study, some of its parts connect with the empirical model used in this paper. The expectancy value model takes into account several factors that potentially influence an intention to pursue a specific goal (in this case, enter a research-oriented career): the expectation of being able to reach the goal, and different aspects of the value of reaching it. Moreover environmental influences should also be taken into account. For instance, research has shown that encouragement from professors might stimulate students to enter graduate school (Eagan Jr et al., 2011; Dasan, 2013; Guerin et al., 2015), the traditional way to a career as a researcher, and that the socialization by family and peers might have an important impact on students' progress (Lamport, 1993; Zafira, 2012; Guerin et al., 2015). Labini and Zinovyeva (2011) also stated that the quality of the research of the university was an important stimulus for students to enroll in a $\mathrm{PhD}$ program, and this was more so in sciences, medicine, and engineering. These factors have to be placed within the culture of the society in which these actors are socialized, which refers to variables such as gender, or domain of study (e.g., science vs. humanities). Future research could benefit from using such broad theories in combination with the results from our empirical model to further refine the theory and to build even better empirical models. 


\section{References}

AcademicPositions.eu. (2016) KU Leuven. Retrieved from http://academicpositions.eu/ employer/ku-leuven/

Bandura, A. (1993). Perceived self-efficacy in cognitive development and functioning. Educational Psychologist, 28(2), 117-148.

Barmby, P., Kind, P. M., \& Jones, K. (2008). Examining changing attitudes in secondary school science. International Journal of Science Education, 30(8), 1075-1093. http://dx.doi.org/10.1080/09500690701344966

Bennett, R. (2009). Academic self-concept among business students in a recruiting university: definition, measurement and potential effects. Journal of Further and Higher Education, 33(2), 141-158. http://dx.doi.org/10.1080/03098770902856678

Bennett, J., \& Hogarth, S. (2009). Would you want to talk to a scientist at a party? High school students' attitudes to school science and to science. International Journal of Science Education, 31(14), 1975-1998. http://dx.doi.org/10.1080/09500690802425581

Bhattacharya, S. (2015). A study on the higher education system in India and factors affecting the choice of teaching career in IT education. Mediterranean Journal of Social Sciences, 6(4 S1), 62-70. http://dx.doi.org/10.5901/mjss.2015.v6n4s1p62

Blickenstaff, J. C. (2005). Women and science careers: leaky pipeline or gender filter. Gender and Education, 17(4), 369-386. http://dx.doi.org/10.1080/09540250500145072

Cheryan, S., \& Plaut, V. C. (2010). Explaining underrepresentation: a theory of precluded interest. Sex Roles, 63, 475-488. http://dx.doi.org/10.1007/s11199-010-9835-x

Cheung, D. (2009). Developing a scale to measure students' attitudes toward chemistry lessons. International Journal of Science Education, 31(16), 2185-2203. http://dx.doi.org/ 10.1080/09500690802189799

Dasan, J. (2013). Pursuing undergraduates' interest on academic career choice. In R. Hamid, G. H. Tanakinjal, L. H. Ann, \& L. L. Majawat (Eds.), Proceedings of the 2nd Applied International Business Conference (AIBC2013) (pp. 665-679). Labuan International Campus: University Malaysia Sabah.

De Wit, K., Heerwegh, D., \& Verhoeven, J. C. (2014). Can openness for ICT and scientific research predict ICT skills and ICT use of bachelor students? Computers \& Education, 78, 397-413. http://dx.doi.org/10.1016/j.compedu.2014.07.003

DiStefano, C., Zhu, M., \& Mîndrilä, D. (2009). Understanding and using factor scores: considerations for the applied researcher. Practical Assessment, Research \& Evaluation, 14(20). Retrieved from http://pareonline.net/getvn.asp?v=14\&n=20

Duffy, R. D., \& Sedlacek, W. E. (2007). What is important to students' long-term career choices: analyzing 10-year trends and group differences. Journal of Career Development, 34(2), 149-163. http://dx.doi.org/10.1177/0894845307307472 
Eagan Jr, M. K., Sharkness, J., Hurtado, S., Mosqueda, C. M., \& Chang, M. J. (2011). Engaging undergraduates in science research: not just about faculty willingness. Research in Higher Education, 52(2), 151-177. http://dx.doi.org/10.1007/s11162-010-9189-9

Eccles, J. (2009). Who am I and what am I going to do with my life? Personal and collective identities as motivators of action. Educational Psychologist, 44(2), 78-89. http://dx.doi.org/ $10.1080 / 00461520902832368$

Eurostat. (2009). Science, technology and Innovation in Europe. Luxembourg: Office for Official Publications of the European Communities. http://dx.doi.org/10.2785/20620

Gainor, K. (2006). Twenty-five years of self-efficacy in career assessment and practice. Journal of Career Assessment, 14(1), 161-178. http://dx.doi.org/10.1177/1069072705282435

George, R. (2006). A cross-domain analysis of change in students' attitudes toward science and attitudes about the utility of science. International Journal of Science Education, 28(6), 571-589. http://dx.doi.org/10.1080/09500690500338755

Gottfredson, L. S. (1981). Circumscription and compromise: A developmental theory of occupational aspirations. Journal of Counseling Psychology, 28(6), 545-579.

Guerin, C., Jayatilaka, A., \& Ranasinghe, D. (2015). Why start a higher degree by research? An exploratory factor analysis of motivations to undertake doctoral studies. Higher Education Research \& Development, 34(1), 89-104. http://dx.doi.org/10.1080/07294360. 2014.934663

Hartman, H., \& Hartman, M. (2008). How undergraduate engineering students perceive women's (and men's) problems in science, math and engineering. Sex Roles, 58(3-4), 251-365. http://dx.doi.org/10.1007/s11199-007-9327-9

Kamphuis, A. M. (2007). Surfing toward a doctoral degree (master thesis). Enschede: University of Twente. Retrieved from http://scripties.ned.ub.rug.nl/search.php?query= Kamphuis\&pSearch=Zoek

Labini, M. S., \& Zinovyeva, N. (2011). Stimulating graduates' research-oriented careers: does academic research matter? Industrial and Corporate Change, 20(1), 337-365. http://dx.doi.org/10.1093/icc/dtq075

Lamport, M. A. (1993). Student-faculty informal interaction and the effect on college student outcomes: a review of the literature. Adolescence, 28(112), 971-990.

Lent, R., Brown, S. D., \& Hackett, G. (1994). Toward a unifying social cognitive theory of career and academic interest, choice, and performance. Journal of Vocational Behavior, 45(1), 79-122.

KU Leuven (2012). Identity and mission of $K U$ Leuven. Retrieved from https://www.kuleuven.be/about/mission_statement

KU Leuven. (2016) High-quality education. Retrieved from https://www.kuleuven.be/ education/high-quality.html 
Lin, C., \& Ha, L. (2009). Subcultures and use of communication information technology in higher education institutions. The Journal of Higher Education, 80(5), 564-590. http://dx.doi.org/10.1353/jhe.0.0064

Messersmith, E. E., Garrett, J. L., Davis-Kean, P. E., Malanchuk, O., \& Eccles, J. S. (2008). Career development from adolescence through emerging adulthood: insights from information technology occupations. Journal of Adolescent Research, 23(2), 206-227. http://dx.doi.org/10.1177/0743558407310723

Mohrman, K., Ma, W., \& Baker, D. (2008). The research university in transition: the emerging global model. Higher Education Policy, 21, 5-27. http://dx.doi.org/10.1057/ palgrave.hep. 8300175

Neice, D. E., \& Bradley, R. W. (1979). Relationship of age, sex, and educational groups to career decisiveness. Journal of Vocational Behavior, 14(3), 271-278.

Osborne, J., Simon, S., \& Collins, S. (2003). Attitudes towards science: A review of the literature and its implications. International Journal of Science Education, 25(9), 1049-1079. http://dx.doi.org/10.1080/0950069032000032199

Pole, C., \& Lampard, R. (2002). Practical Social Investigation. Qualitative and Quantitative Methods in Social Research. Harlow: Prentice Hall.

Potvin, P., \& Hasni, A. (2014). Analysis of the decline in interest towards school science and technology from grades 5 through 11. Journal of Science Education and Technology, 23(6), 784-802. http://dx.doi.org/10.1007/s10956-014-9512-x

Rottinghaus, P., Lindley, L. D., Green, M. A., \& Borgen, F. H. (2002). Educational aspirations: the contribution of personality, self-efficacy, and interests. Journal of Vocational Behavior, 61(1), 1-19. http://dx.doi.org/10.1006/jvbe.2001.1843

Silvestrini, G. V. (2013). Toward knowledge societies. In A. M. Bruyas, \& M. Riccio (Eds.), Science Centres and Science Events (pp. 9-13). Mailand: Springer-Verlag Italia. http://dx.doi.org/10.1007/978-88-470-2556-1_2

Uhlir, P. F., \& Schröder, P. (2007). Open data for global science. Data Science Journal, 6(Open Data Issue), OD36-OD53. http://doi.org/10.2481/dsj.6.OD36

Venville, G., Rennie, L., Hanbury, C., \& Longnecker, N. (2013). Scientists reflect on why they chose to study science. Research in Science Education, 43(6), 2207-2233. http://dx.doi.org/10.1007/s11165-013-9352-3

Verhoeven, J. C., Heerwegh, D., \& De Wit, K. (2016). ICT learning experience and research orientation as predictors of ICT skills and the ICT use of university students. Education and Information Technologies, 21(1), 71-103. http://dx.doi.org/10.1007/s10639-014-9310-3

Vermunt, J. (1994). Scoring key for the inventory of learning styles (ILS) in higher education. Tilburg: Tilburg University.

Wertheim, E. G., Widom, C. S., \& Wortzel, L. H. (1978). Multivariate analysis of male and 


\section{Macrothink}

female professional career choice correlates. Journal of Applied Psychology, 63(2), 234-242.

Woolnough, B. E. (1994). Factors affecting students' choice of science and engineering. International Journal of Science Education, 16(6), 659-676.

Zafira, D. (2012). Persistent inequality or liberation from social origins? Determining who attends graduate and professional schools in Canada's expanded postsecondary system. Canadian Review of Sociology/Revue Canadienne de Sociologie., 49(2), 109-137. http://dx.doi.org/10.1111/j.1755-618X.2011.01286.x

\section{Copyright Disclaimer}

Copyright reserved by the author(s).

This article is an open-access article distributed under the terms and conditions of the Creative Commons Attribution license (http://creativecommons.org/licenses/by/3.0/). 